\title{
microRNA-based biomarkers and the diagnosis of Alzheimer's disease
}

\author{
Yuhai Zhao ${ }^{1,2}$, Surjyadipta Bhattacharjee ${ }^{1}$, Prerna Dua ${ }^{3}$, Peter N. Alexandrov ${ }^{4}$ and \\ Walter J. Lukiw ${ }^{1,5,6 *}$
}

${ }^{1}$ LSU Neuroscience Center Louisiana State University Health Science Center, New Orleans, LA, USA, ${ }^{2}$ Department of Cell Biology and Anatomy, LSU Neuroscience Center Louisiana State University Health Science Center, New Orleans, LA, USA, ${ }^{3}$ Department of Health Information Management, Louisiana State University, Ruston, LA, USA, ${ }^{4}$ Russian Academy of Medical Sciences, Moscow, Russia, ${ }^{5}$ Department of Ophthalmology, LSU Neuroscience Center Louisiana State University Health Science Center, New Orleans, LA, USA, ${ }^{6}$ Department of Neurology, LSU Neuroscience Center Louisiana State University Health Science Center, New Orleans, LA, USA

Keywords: aging, Alzheimer's disease, diagnostic panel, heterogeneity, human biochemical individuality, inflammation, microRNA, prion disease

\section{OPEN ACCESS}

Edited by:

Charlotte Elisabeth Teunissen, VU University Medical Center Amsterdam, Netherlands

Reviewed by:

Cees Oudejans,

VU University Medical Center Amsterdam, Netherlands Argonde Corien Van Harten,

VU University Medical Center Amsterdam, Netherlands

*Correspondence: Walter J. Lukiw wlukiw@/suhsc.edu

Specialty section: This article was submitted to Neurodegeneration, a section of the journal Frontiers in Neurology

Received: 25 May 2015 Accepted: 29 June 2015 Published: 13 July 2015

Citation:

Zhao Y, Bhattacharjee S, Dua $P$, Alexandrov PN and Lukiw WJ (2015) microRNA-based biomarkers and the diagnosis of Alzheimer's disease. Front. Neurol. 6:162. doi: 10.3389/fneur.2015.00162
Alzheimer's disease $(\mathrm{AD})$ is characterized as a complex, age-related neurological disorder of the human central nervous system (CNS) that involves the progressive mis-regulation of multiple biological pathways at multiple molecular, genetic, epigenetic, neurophysiological, cognitive, and behavioral levels. It has been about 8 years since the first reports of altered microRNA (miRNA) abundance and speciation: (i) in anatomical regions of the brain targeted by the AD process after post-mortem examination, (ii) in blood serum, and (iii) in cerebrospinal fluid (CSF) (1-3). Since then an in depth overview of the peer-reviewed literature has provided no general consensus of what miRNAs are up-or-down regulated in any tissue or biofluid compartment in thousands of AD patients. In this brief "Opinion" paper on "Biomarkers of Alzheimer's disease: the present and the future," we will highlight the extremely heterogeneous nature of miRNA expression in $\mathrm{AD}$, based on very recent advances in the analysis of miRNA populations in various biofluid compartments compared to normally aging, neurologically normal controls. This work is based against a background of our laboratory's 24 years of research experience into the structure and function of small, non-coding RNAs in the aging human CNS in health and in age-related neurological disease (4).

First, it is important to appreciate that all forms of dementia due to $\mathrm{AD}$ are broadly classified as either early onset (EOAD, under 65 years of age), or late onset (LOAD, over 65 years of age) $(5,6)$. About $\sim 5 \%$ of all $\mathrm{AD}$ cases have a genetic component (see below) while the remaining $\sim 95 \%$ of all $\mathrm{AD}$ cases are of a sporadic (idiopathic) nature or are of unknown origin (5-8). The extremely heterogeneous nature of $\mathrm{AD}$ pervades all molecular, genetic, neuropathological and behavioral, mnemonic, and cognitive levels, including the clinical presentation of the disease (615). For example, the key neuropathological markers of $\mathrm{AD}$ include: (i) the progressive deposition of amyloid-beta $(\mathrm{A} \beta$ ) peptides into dense, insoluble pro-inflammatory senile plaques (SP); (ii) the accumulation of hyperphosphorylated tau into neurofibrillary tangles (NFT); (iii) synaptic atrophy, "pruning" and loss, neuronal degeneration and neuronal cell death; (iv) alterations in the innate-immune response; and (v) the progressive inflammatory neurodegeneration and anatomical targeting of only specific anatomical regions of the brain (1-15). These highly interactive characteristics collectively suggest the participation of multiple pathogenic pathways, and the involvement of multiple deficits in the expression of CNS genes (1-15). Accordingly, this culminates in a remarkably heterogeneous neuropathological scaffold for $\mathrm{AD}$, with significant variations in disease onset, progression, severity of neuropathology, extent of behavioral and cognitive deficits, and memory loss (4-12). To cite one very recent example, a relatively large epidemiological study of

Abbreviations: miRNA, microRNA. 
AD patient data $(N=7815)$ (12) indicated significant heterogeneity in the first cognitive/behavioral symptomatic "indicator" experienced by $\mathrm{AD}$ patients (13-16). In other recent studies, two laboratories have independently reported significant variation in the miRNA-34a-mediated triggering receptor expressed in myeloid/microglial cells-2 (TREM2) down-regulation in an African-American population that further underscores (i) the importance of investigating different ethnic populations for $\mathrm{AD}$ epigenetic risk; (ii) intrinsic variance and human biochemical and genetic individuality; and (iii) allelic heterogeneity and potentially diverse pathogenic contributory mechanisms to the AD process (sufficient TREM2 is important in the clearance of excessive A $\beta$ peptides from the brain) (9-16). Related to these observations are studies that over the last 15 years have indicated that gene expression patterns at the messenger RNA (mRNA) level, A $\beta$ peptide load, SP and NFT densities and localization, and familial and clinical histories further underscore AD heterogeneity $(8-12,17$ 20). Indeed, there appears to be intrinsic limitations of useful AD biomarkers because just one biomarker cannot define the mechanism of $\mathrm{AD}$, by nature are associative and/or correlative, and are unable to unequivocally prove disease causality (13-17, 21-23). For example current genome-wide association studies (GWAS), whole-exome and whole-genome sequencing have revealed mutations in excess of 20 genetic loci associated with $\mathrm{AD}$ risk $(11,19$, 20, 24). Three main genes are involved in EOAD: amyloid precursor protein $(A P P)$, presenilin 1 (PSEN1), and presenilin 2 (PSEN2), while the apolipoprotein $E(A p o E) \mathrm{E} 4$ allele has been found to be a main risk factor for $\operatorname{LOAD}(1,17-19,23)$. Additionally, recent studies have discovered other genes that might be peripherally involved in $\mathrm{AD}$, including clusterin $(C L U)$, complement receptor 1 (CR1), phosphatidylinositol binding clathrin assembly protein (PICALM), sortilin-related receptor (SORL1), complement factor $\mathrm{H}(\mathrm{CFH})$, the triggering receptor expressed on myeloid/microglial cells 2 (TREM2), and the cluster of differentiation 33 (CD33) gene loci; although not one single case of $\mathrm{AD}$ has yet been found to be associated with more than one of these aberrant genetic loci (11, $25)$. Indeed, most $\mathrm{AD}$ cases do not contain any of these mutant genetic "biomarkers" (11, 20, 24-26). Further, the persistence of mutations in these genes from birth and throughout life, in contrast to the general development of $\mathrm{AD}$ in old age, suggests that multiple age-associated gene regulatory mechanisms must come into play to initiate and drive development and propagation of the $\mathrm{AD}$ process, and miRNAs are excellent candidates for these diverse age-related, developmental, and regulatory roles $(1-5,9,22)$.

Regarding the rate and variability of cognitive decline in $\mathrm{AD}$, one large recent study did not find evidence supporting a substantial role of the mini-mental status examination (MMSE) as a stand-alone single-administration test in the identification of mild cognitively impaired patients who eventually develop $\mathrm{AD}$, suggesting the need for additional neuropsychological testing and comprehensive biomarker analysis (21-23). Indeed, although $\mathrm{AD}$ is the most common form of senile dementia, it can often be challenging to distinguish this insidious and fatal disorder from other equally heterogeneous neurodegenerative disorders, such as frontal temporal dementia, human prion disease [including bovine spongiform encephalopathy (BSE; mad cow disease), Creutzfeldt-Jakob disease, Gerstmann-Sträussler-Scheinker syndrome, and other relatively rare human prion diseases], Huntington's disease, Lewy Body dementia, Parkinson's disease, cerebrovascular disease, or vascular (multiple infarct) dementia (16-18, 21-23). Indeed, the diagnostic accuracy of when brain-mediated cognitive deficits actually begin may require a dimensional rather than a categorical classification, and a lifespan rather than aging grouping, and it has been recently suggested that a multidimensional system-vulnerability approach rather than a simple "hypothetical biomarker" model of age-associated cognitive decline and dementia may be more useful diagnostically $(12,20)$. Put another way, $\mathrm{AD}$ might be classified not as a discrete disease entity but rather as a "neurological disconnection syndrome" $(7,8,11,15,24)$. This "neurological disconnection syndrome" is more broadly defined as an abnormal condition characterized by an established group of variable neurological signs, symptoms, and molecular markers, including miRNA abundance and speciation, that individually possess only limited neuropathological and cognition/behavioral similarities from patient to patient (7-9, 11-18, 21-24).

Further to the concept of $\mathrm{AD}$ heterogeneity are the ideas that form the conceptual basis for "human biochemical and genetic individuality" $(5,9,18)$. These include individual gene sequence variation, gene-based susceptibility to disease and heterogeneity in miRNA abundance and complexity, that may in part drive a general redundancy in gene expression in different human populations $(5,9,16,21,22)$. Interestingly, these variations may directly impact the genetic evolution of the human species $(4,5,18-20,24-$ 26). Much independently derived data support the concept that the genetics, epigenetics, and genome-wide regulatory networks of $\mathrm{AD}$ vary considerably among different human populations that possess different genetic and/or environmental backgrounds. Furthermore, despite the fact that genetic factors are inherited and fixed, non-genetic factors, such as (i) environmental or occupational exposures to pesticides, organic solvents, anesthetics, and/or food additives; (ii) pre-existing medical conditions such as cancer, cerebrovascular, and/or cardiovascular disease, depression, diabetes, dyslipidemia, hypertension, traumatic brain injury, older age, female gender, and ApoE status; and (iii) lifestyle factors such as alcohol and coffee consumption, salt, sugar, and cholesterol and fat intake, body mass index, cognitive activity, physical activity, and smoking, are life-style determined and these are known to impact the incidence, development and propagation of AD (18-20, 24-31). Interestingly, certain potentially pathogenic "pro-inflammatory miRNAs" of the host are significantly inducible by common microbial and environmental factors such as herpes simplex-1 virus (HSV-1) and naturally occurring elements of the biosphere (such as aluminum oxides that make up almost $9 \%$ of the earth's crust) (32-35).

To make another important point concerning the variable contribution of specific miRNAs to AD, we surveyed the most recently published papers on " $m i R N A$ biomarkers for $A D$ ” using the National Institutes of Health National Library of Medicine website MedLine (www.ncbi.nlm.nih.gov; using the keywords "Alzheimer's disease," "miRNA" and "2015"). The most recent findings of 15 independent labs further support the contention of extremely high miRNA heterogeneity in $\mathrm{AD}$ tissue and biofluids (36-50). For example, the last 15 reports of diagnostic markers 
in AD CSF (36-39; involving miRNA-27a, miRNA-29a, miRNA191, miRNA-384) and others, AD blood serum (38-46; involving miRNA-107, miRNA-125b, miRNA-128, miRNA-132, miRNA191, miRNA-206, miRNA-384) and others; "humanized" AD cell models (47-50; involving miRNA-125b, miRNA-128, miRNA138) and others, and several recent reviews (51-55) provides no common or general consensus of any single miRNA that defines causality for the onset or duration of the AD process. To further complicate these findings, recent molecular-genetic studies have also shown that even when derived from homogenous source populations, such as pluripotent stem cells, individual cells from those populations exhibit significant differences in gene expression, protein abundance and phenotypic output; here specific families of miRNAs appear to have a deterministic role in reconfiguring the "pluripotency network" of individual cells with important downstream functional consequences $(47-49,56,57)$.

It is further important to point out exactly what an advanced analytical technique will tell us. For example, most AD researchers would agree that the production of $\mathrm{A} \beta 42$ peptides is involved in the $\mathrm{AD}$ process. $\mathrm{A} \beta 42$ peptides and fragments are generated by a variety of secretases (chiefly $\alpha$-, $\beta$-, and $\gamma$-secretases), however, other secretase-like enzymes and enzyme modifiers appear to be involved (5, 8, 14, 25, 31, 58). While RNA-seq and other "next generation sequencing" (NGS) methods will tell us something about the levels of expression of these secretases they would give us no clue about the activity of these secretases in the brain, and their ability to generate $\mathrm{A} \beta 42$ or other $\mathrm{AD}$-relevant peptides, which are affected by many other genetic, epigenetic, non-genetic, environmental, and host lifestyle factors. So it is unlikely that RNA-seq, NGS, or other "advanced sequencing methodologies" could give us the entire story of what is going on in $\mathrm{AD}$, although most agree it would give us very valuable insight as to what is happening at the molecular-genetic level, and perhaps be of some value diagnostically.

Lastly, if high-density microarray- and advanced RNAsequencing based profiles of $\mathrm{AD}$ brain or biofluid samples are any indication of $\mathrm{AD}$ variability then there are real and significant human population differences in $\mathrm{AD}$ onset, incidence, epidemiology, disease course and progression $(9,16,21,22,25$, $50,57)$. It is unlikely that a single miRNA in the CSF, blood serum, urine, or any other biofluid compartments from multiple human populations will be predictive for $\mathrm{AD}$ at any stage of the disease. However, what might be particularly useful for significantly improved AD diagnostics would be a selective, highdensity panel of a "pathogenic and neurodegeneration-associated miRNA family" that along with other gene expression-based

\section{References}

1. Lukiw WJ. MiRNA speciation in fetal, adult and Alzheimer's disease hippocampus. Neuroreport (2007) 18:297-300. doi:10.1097/WNR.0b013e3280148e8b

2. Schipper HM, Maes OC, Chertkow HM, Wang E. MicroRNA expression in Alzheimer blood mononuclear cells. Gene Regul Syst Bio (2007) 1:263-74.

3. Cogswell JP, Ward J, Taylor IA, Waters M, Shi Y, Cannon B, et al. Identification of miRNA changes in Alzheimer's disease brain and CSF yields putative biomarkers and insights into disease pathways. J Alzheimers Dis (2008) 14(1):27-41. biometrics could more accurately predict the onset of $\mathrm{AD}$ type change. This highly interactive, "personalized medicine" approach - involving a comprehensive evaluation that scores multiple $\mathrm{AD}$ deficiencies including miRNA-, mRNA-, and protein-based gene expression alterations, AD-relevant DNA mutations, pro-inflammatory biomarkers (such as C-reactive protein or CRP), and $A \beta 40$ - and $A \beta 42$-peptide load in the CSF and blood serum, combined with data from MRI- and PETbased brain imaging, and familial, clinical history, lifestyle, and other factors could be extremely useful in the improved diagnosis of $\mathrm{AD}$ susceptibility and development (52-58). These highly integrated and multidimensional diagnostic approaches certainly lie within the grasp of current medical technologies it will just be a matter of improved application, data acquisition and integration of clinical research and healthcare resources to frame a more accurate diagnostic portrait of the "alleged $A D$ patient." Indeed, an equally wide variety of individualistic prevention and "personalized" treatment strategies would be required to more effectively address such age-related neurological disorders, including the implementation of combinatorial and/or customized anti-miRNA strategies that have as yet not been considered.

\section{Acknowledgments}

This work was presented in part at the Society for Neuroscience (SFN) Annual Meeting 15-19 November 2014, Washington, DC, USA and at the Association for Research in Vision and Ophthalmology (ARVO) Annual conference 3-7 May 2015 in Denver, CO, USA. Sincere thanks are extended to Drs. L. Carver, E. Head, W. Poon, H. LeBlanc, F. Culicchia, C. Eicken, and C. Hebel for short post-mortem interval (PMI) human brain and/or retinal tissues or extracts, miRNA array work and initial data interpretation, and to D. Guillot and A. I. Pogue for expert technical assistance. Thanks are also extended to the many neuropathologists, physicians, and researchers of Canada and the US, who have provided high quality, short PMI human CNS and retinal tissues or extracted total brain and retinal RNA for scientific study. Research on miRNA in the Lukiw laboratory involving the innate-immune response in $\mathrm{AD}, \mathrm{AMD}$, and in other forms of neurological or retinal disease, amyloidogenesis, and neuro-inflammation was supported through an unrestricted grant to the LSU Eye Center from Research to Prevent Blindness (RPB); the Louisiana Biotechnology Research Network (LBRN), and NIH grants NEI EY006311, NIA AG18031, and NIA AG038834.

4. Lukiw WJ, Handley P, Wong L, Crapper McLachlan DR. BC200 RNA in normal human neocortex, non-Alzheimer dementia (NAD), and senile dementia of the Alzheimer type (AD). Neurochem Res (1992) 17:591-7. doi:10.1007/ BF00968788

5. Jiang T, Yu JT, Tian Y, Tan L. Epidemiology and etiology of Alzheimer's disease: from genetic to non-genetic factors. Curr Alzheimer Res (2013) 10:852-67. doi:10.2174/15672050113109990155

6. Guerreiro RJ, Gustafson DR, Hardy J. The genetic architecture of Alzheimer's disease: beyond APP, PSENs and APOE. Neurobiol Aging (2012) 33:437-56. doi:10.1016/j.neurobiolaging.2010.03.025 
7. Canobbio I, Abubaker AA, Visconte C, Torti M, Pula G. Role of amyloid peptides in vascular dysfunction and platelet dysregulation in Alzheimer's disease. Front Cell Neurosci (2015) 9:65. doi:10.3389/fncel.2015.00065

8. Kim DH, Yeo SH, Park JM, Choi JY, Lee TH, Park SY, et al. Genetic markers for diagnosis and pathogenesis of Alzheimer's disease. Gene (2014) 545:185-93. doi:10.1016/j.gene.2014.05.031

9. Lukiw WJ. Variability in micro RNA (miRNA) abundance, speciation and complexity amongst different human populations and potential relevance to Alzheimer's disease (AD). Front Cell Neurosci (2013) 7:133. doi:10.3389/fncel. 2013.00133

10. Sherva R, Tripodis Y, Bennett DA, Chibnik LB, Crane PK, de Jager PL, et al. Genome-wide association study of the rate of cognitive decline in Alzheimer's disease. Alzheimers Dement (2014) 10:45-52. doi:10.1016/j.jalz.2013.01.008

11. Jin SC, Carrasquillo MM, Benitez BA, Skorupa T, Carrell D, Patel D, et al. TREM2 is associated with increased risk for Alzheimer's disease in African Americans. Mol Neurodegener (2015) 10:19-26. doi:10.1186/ s13024-015-0016-9

12. Barnes J, Dickerson BC, Frost C, Jiskoot LC, Wolk D, van der Flier WM. Alzheimer's disease first symptoms are age dependent: evidence from the NACC dataset. Alzheimers Dement (2015). doi:10.1016/j.jalz.2014.12.007

13. Verhülsdonk S, Hellen F, Höft B, Supprian T, Lange-Asschenfeldt C. Attention and CERAD test performances in cognitively impaired elderly subjects. Acta Neurol Scand (2015) 131:364-71. doi:10.1111/ane.12346

14. Praticò D. Alzheimer's disease and the quest for its biological measures. J Alzheimers Dis (2013) 33:S237-41. doi:10.3233/JAD-2012-129023

15. Wang Z, Wang J, Zhang H, Mchugh R, Sun X, Li K, et al. Interhemispheric functional and structural disconnection in Alzheimer's disease: a combined resting-state fMRI and DTI Study. PLoS One (2015) 10(5):e0126310. doi:10. 1371/journal.pone.0126310

16. Walhovd KB, Fjell AM, Espeseth T. Cognitive decline and brain pathology in aging-need for a dimensional, lifespan and systems vulnerability view. Scand J Psychol (2014) 55:244-54. doi:10.1111/sjop.12120

17. Kim MO, Geschwind MD. Clinical update of Jakob-Creutzfeldt disease. Curr Opin Neurol (2015) 28:302-10. doi:10.1097/WCO.0000000000000197

18. Li JQ, Tan L, Wang HF, Tan MS, Tan L, Xu W, et al. Risk factors for predicting progression from mild cognitive impairment to Alzheimer's disease: a systematic review and meta-analysis of cohort studies. J Neurol Neurosurg Psychiatry (2015). doi:10.1136/jnnp-2014-310095

19. Colangelo V, Schurr J, Ball MJ, Pelaez RP, Bazan NG, Lukiw WJ. Gene expression profiling of 12633 genes in Alzheimer hippocampal CA1. J Neurosci Res (2002) 70:462-73. doi:10.1002/jnr.10351

20. Loring JF, Wen X, Lee JM, Seilhamer J, Somogyi R. A gene expression profile of Alzheimer's disease. DNA Cell Biol (2002) 20:683-95. doi:10.1089/ 10445490152717541

21. Arevalo-Rodriguez I, Smailagic N, Roqué I, Figuls M, Ciapponi A, SanchezPerez E, et al. Mini-Mental State Examination (MMSE) for the detection of Alzheimer's disease and other dementias in people with mild cognitive impairment (MCI). Cochrane Database Syst Rev (2015) 3:CD010783. doi:10.1002/ 14651858.CD010783.pub2

22. Blennow K, Dubois B, Fagan AM, Lewczuk P, de Leon MJ, Hampel H. Clinical utility of cerebrospinal fluid biomarkers in the diagnosis of early Alzheimer's disease. Alzheimers Dement (2015) 11(1):58-69. doi:10.1016/j.jalz.2014.02.004

23. Chitravas N, Jung RS, Kofskey DM, Blevins JE, Gambetti P, Leigh RJ, et al. Treatable neurological disorders misdiagnosed as Creutzfeldt-Jakob disease. Ann Neurol (2011) 70(3):437-44. doi:10.1002/ana.22454

24. Counts SE, Alldred MJ, Che S, Ginsberg SD, Mufson EJ. Synaptic gene dysregulation within hippocampal CA1 pyramidal neurons in mild cognitive impairment. Neuropharmacology (2014) 79:172-9. doi:10.1016/j.neuropharm. 2013.10.018

25. Chouraki V, Seshadri S. Genetics of Alzheimer's disease. Adv Genet (2014) 87:245-94. doi:10.1016/B978-0-12-800149-3.00005-6

26. Tan MS, Jiang T, Tan L, Yu JT. Genome-wide association studies in neurology. Ann Transl Med (2014) 2:124. doi:10.3978/j.issn.2305-5839.2014.11.12

27. Tai LM, Ghura S, Koster KP, Liakaite V, Maienschein-Cline M, Kanabar P, et al. APOE-modulated A $\beta$-induced neuroinflammation in Alzheimer's disease. J Neurochem (2015) 133:465-88. doi:10.1111/jnc.13072

28. Yaghmoor F, Noorsaeed A, Alsaggaf S, Aljohani W, Scholtzova H, Boutajangout A, et al. The role of TREM2 in Alzheimer's disease and other neurological disorders. J Alzheimers Dis Parkinsonism (2014) 4(5):160. doi:10.4172/2161-0460. 1000160
29. Cheng XJ, Gao Y, Zhao YW, Cheng XD. Sodium chloride increases A $\beta$ Levels by suppressing A $\beta$ clearance in cultured cells. PLoS One (2015) 10:e0130432. doi:10.1371/journal.pone.0130432

30. Baumgart M, Snyder HM, Carrillo MC, Fazio S, Kim H, Johns H. Summary of the evidence on modifiable risk factors for cognitive decline and dementia: a population-based perspective. Alzheimers Dement (2015) 11:718-26. doi:10. 1016/j.jalz.2015.05.016

31. Østergaard SD, Mukherjee S, Sharp SJ, Proitsi P, Lotta LA, Day F, et al. Associations between potentially modifiable risk factors and Alzheimer disease. PLoS Med (2015) 12:e1001841. doi:10.1371/journal.pmed.1001841

32. Bhela S, Mulik S, Reddy PB, Richardson RL, Gimenez F, Rajasagi NK, et al. Critical role of microRNA-155 in herpes simplex encephalitis. Jimmunol (2014) 192:2734-43. doi:10.4049/jimmunol.1302326

33. Hill JM, Clement C, Zhao Y, Lukiw WJ. Induction of the pro-inflammatory NF-kB-sensitive miRNA-146a by human neurotrophic viruses. Front Microbiol (2015) 6:43. doi:10.3389/fmicb.2015.00043

34. Alexandrov PN, Zhao Y, Jones BM, Bhattacharjee S, Lukiw WJ. Expression of the phagocytosis-essential protein TREM2 is down-regulated by an aluminuminduced miRNA-34a in a murine microglial cell line. J Inorg Biochem (2013) 128:267-9. doi:10.1016/j.jinorgbio.2013.05.010

35. Pogue AI, Percy ME, Cui JG, Li YY, Bhattacharjee S, Hill JM, et al. Upregulation of NF-kB-sensitive miRNA-125b and miRNA-146a in metal sulfatestressed human astroglial (HAG) primary cell cultures. J Inorg Biochem (2011) 105:1434-7. doi:10.1016/j.jinorgbio.2011.05.012

36. Müller M, Jäkel L, Bruinsma IB, Claassen JA, Kuiperij HB, Verbeek MM. microRNA-29a is a candidate biomarker for Alzheimer's disease in cell-free cerebrospinal fluid. Mol Neurobiol (2015). doi:10.1007/s12035-015-9156-8

37. Sala Frigerio C, Lau P, Salta E, Tournoy J, Bossers K, Vandenberghe R, et al. Reduced expression of hsa-miR-27a-3p in CSF of patients with Alzheimer disease. Neurology (2013) 81:2103-6. doi:10.1212/01.wnl.0000437306.37850.22

38. Liu CG, Wang JL, Li L, Wang PC. MicroRNA-384 regulates both amyloid precursor protein and $\beta$-secretase expression and is a potential biomarker for Alzheimer's disease. Int J Mol Med (2014) 34:160-6. doi:10.3892/ijmm.2014. 1780

39. Nagpal N, Kulshreshtha R. miR-191: an emerging player in disease biology. Front Genet (2014) 5:99. doi:10.3389/fgene.2014.00099

40. Wang T, Chen K, Li H, Dong S, Su N, Liu Y, et al. The feasibility of utilizing plasma miRNA107 and BACE1 messenger RNA gene expression for clinical diagnosis of amnestic mild cognitive impairment. J Clin Psychiatry (2015) 76:135-41. doi:10.4088/JCP.13m08812

41. Xie B, Zhou H, Zhang R, Song M, Yu L, Wang L, et al. Serum miR-206 and miR-132 as potential circulating biomarkers for mild cognitive impairment. J Alzheimers Dis (2015) 45:721-31. doi:10.3233/JAD- 142847

42. Tan L, Yu JT, Liu QY, Tan MS, Zhang W, Hu N, et al. Circulating miR-125b as a biomarker of Alzheimer's disease. J Neurol Sci (2014) 336:52-6. doi:10.1016/j. jns.2013.10.002

43. Tiribuzi R, Crispoltoni L, Porcellati S, Di Lullo M, Florenzano F, Pirro M, et al. miR128 up-regulation correlates with impaired amyloid $\beta(1-42)$ degradation in monocytes from patients with sporadic Alzheimer's disease. Neurobiol Aging (2014) 35:345-56. doi:10.1016/j.neurobiolaging.2013.08.003

44. Leidinger P, Backes C, Deutscher S, Schmitt K, Mueller SC, Frese K, et al. A blood based 12-miRNA signature of Alzheimer disease patients. Genome Biol (2013) 14:R78. doi:10.1186/gb-2013-14-7-r78

45. Satoh J, Kino Y, Niida S. MicroRNA-seq data analysis pipeline to identify blood biomarkers for Alzheimer's disease from public data. Biomark Insights (2015) 10:21-31. doi:10.4137/BMI.S25132

46. Burgos K, Malenica I, Metpally R, Courtright A, Rakela B, Beach T, et al. Profiles of extracellular miRNA in CSF and serum from patients with Alzheimer's and Parkinson's diseases correlate with disease status and features of pathology. PLoS One (2014) 9:e94839. doi:10.1371/journal.pone.0094839

47. Gstir R, Schafferer S, Scheideler M, Misslinger M, Griehl M, Daschil N, et al. Generation of a neurospecific microarray reveals novel differentially expressed noncoding RNAs in mouse models for neurodegenerative diseases. RNA (2014) 20:1929-43. doi:10.1261/rna.047225.114

48. Kumar RM, Cahan P, Shalek AK, Satija R, Daley Keyser AJ, Li H, et al. Deconstructing transcriptional heterogeneity in pluripotent stem cells. Nature (2014) 516:56-61. doi:10.1038/nature13920

49. Patel AP, Tirosh I, Trombetta JJ, Shalek AK, Gillespie SM, Wakimoto H, et al. Single-cell RNA-seq highlights intratumoral heterogeneity in primary glioblastoma. Science (2015) 344:1396-401. doi:10.1126/science.1254257 
50. Danborg PB, Simonsen AH, Waldemar G, Heegaard NH. The potential of miRNAs as biofluid markers of neuro-degenerative disease - a systematic review. Biomarkers (2014) 19:259-68. doi:10.3109/1354750X.2014.904001

51. Wang X, Tan L, Lu Y, Peng J, Zhu Y, Zhang Y, et al. MicroRNA-138 promotes tau phosphorylation by targeting retinoic acid receptor alpha. FEBS Lett (2015) 589:726-9. doi:10.1016/j.febslet.2015.02.001

52. Femminella GD, Ferrara N, Rengo G. The emerging role of microRNAs in Alzheimer's disease. Front Physiol (2015) 6:40. doi:10.3389/fphys.2015.00040

53. Cheng L, Quek CY, Sun X, Bellingham SA, Hill AF. The detection of microRNA associated with Alzheimer's disease in biological fluids using next-generation sequencing technologies. Front Genet (2013) 4:150. doi:10.3389/fgene.2013. 00150

54. Koh W, Pan W, Gawad C, Fan HC, Kerchner GA, Wyss-Coray T, et al. Noninvasive in vivo monitoring of tissue-specific global gene expression in humans. Proc Natl Acad Sci U S A (2014) 111:7361-6. doi:10.1073/pnas.1405528111

55. Grasso M, Piscopo P, Confaloni A, Denti MA. Circulating miRNAs as biomarkers for neurodegenerative disorders. Molecules (2014) 19:6891-910. doi:10. 3390/molecules19056891
56. Liu ZP. Reverse engineering of genome-wide gene regulatory networks from gene expression data. Curr Genomics (2015) 16:3-22. doi:10.2174/ 1389202915666141110210634

57. Li Y, Zhang Z. Computational Biology in microRNA. Wiley Interdiscip Rev RNA (2015) 6(4):435-52. doi:10.1002/wrna.1286

58. Michaud M, Balardy L, Moulis G, Gaudin C, Peyrot C, Vellas B, et al. Proinflammatory cytokines, aging, and age-related diseases. J Am Med Dir Assoc (2013) 14:877-82. doi:10.1016/j.jamda.2013.05.009

Conflict of Interest Statement: The authors declare that the research was conducted in the absence of any commercial or financial relationships that could be construed as a potential conflict of interest.

Copyright (C) 2015 Zhao, Bhattacharjee, Dua, Alexandrov and Lukiw. This is an openaccess article distributed under the terms of the Creative Commons Attribution License (CC BY). The use, distribution or reproduction in other forums is permitted, provided the original author(s) or licensor are credited and that the original publication in this journal is cited, in accordance with accepted academic practice. No use, distribution or reproduction is permitted which does not comply with these terms. 